\title{
Disposition of 3-(4-cyano-2-oxobutylidene amino)-2- oxazolidone, a cyano-metabolite of furazolidone, in furazolidone-treated grouper
}

\author{
Jiin-Ju Guott, Hong-Nong Chou $\dagger^{* *}$ and \\ I. Chiu Liao $\$$ \\ $\dagger$ Institute of Fisheries Science, National Taiwan University, Taipei \\ 106, Taiwan \\ \$ Tungkang Marine Laboratory, Taiwan Fisheries Research Insti- \\ tute, Pingtung 928, Taiwan \\ $\S$ Taiwan Fisheries Research Institute, Keelung 202, Taiwan
}

(Received 24 May 2002; revised 8 September 2002; accepted 19 September 2002)

The cyano-metabolite of furazolidone (FZ), 3-(4cyano-2-oxobutylidene amino)-2-oxazolidone, was isolated from the mixture of FZ incubated with the post$9000 \mathrm{~g}$ hepatic supernatant of grouper. Its structure was confirmed by mass spectrometric and nuclear magnetic resonance spectroscopic studies. Thereafter, the disposition of the cyano-metabolite in the orange-spotted grouper (Epinephelus coioides) after oral and bath treatment with FZ was investigated. Qualitative and quantitative analyses of cyano-metabolite in the fish were performed by high-performance liquid chromatography. Mean recoveries of the metabolite in serum, muscle, liver and kidney were 99.8 $\pm 4.1,98.6 \pm 3.5$, $53.1 \pm 7.4$ and $64.011 .4 \%$, respectively. Cyano-metabolite was mainly distributed in the serum and muscle rather than in the liver and kidney. After oral treatment of FZ, the peak cyano-metabolite concentrations, $167.2 \mathrm{n} \mathrm{ml}^{-1}$ in serum and $283.2 \mathrm{ng} \mathrm{g}^{-1}$ in muscle, were reached at 5.1 and $6.7 \mathrm{~h}$, respectively. The elimination half-life of cyano-metabolite was $4 \mathrm{~h}$. During 24- $h$ bath treatment of $F Z$, the maximum concentrations of cyano-metabolite, $258 \mathrm{ng} \mathrm{ml}^{-1}$ in serum and $204 \mathrm{ng} \mathrm{g}^{-1}$ in muscle, were found at 0.25 and $6 \mathrm{~h}$, respectively. The half-life of cyano-metabolite was $0.5 \mathrm{~h}$ after transferring the fish to fresh seawater.
Keywords : distribution, elimination, cyano-metabolite, furazolidone, grouper, marine fish

\section{Introduction}

Furazolidone (FZ, figure 1) is the major nitrofuran drug widely used as an antibacterial agent in livestock and aquaculture industries. Because of its mutagenic and carcinogenic properties, drug residues should be avoided in edible tissues of animals treated with the drug. Earlier studies showed that no residues of FZ could be detected in edible tissues of fish 1 day after dosing (Sugimoto et al. 1979, Plakas et al. 1994, Guo et al. 2002). However, it was reported that radioactivity could still be detected in tissues of catfish 7 days after oral administration of ${ }^{14} \mathrm{C}-\mathrm{FZ}$ (Plakas et al. 1994). FZ is degraded rapidly and extensively in vivo. Reduction of the nitro group, resulting in the formation of an open-chain cyano-metabolite, is an important metabolic pathway of nitrofurans (Swaminathan and Lower 1978). Some metabolic fates of FZ were examined in rats, swine, eel, trout and Escherichia coli (Tatsumi et al. 1981, Abraham et al. 1984, Nakabeppu and Tatsumi 1984, Vroomen et al. 1987a-c, Hoogenboom et al. 1989, Law et al. 1992 , Law and Meng 1996). The cyano-metabolite 3-(4cyano-2-oxobutylidene amino)-2-oxazolidone (figure $1)$, plays an important role among the major metabolites of FZ for its covalent binding with protein and DNA in vivo (Vroomen et al. 1986).

Marine fish aquaculture is an important industry in Asia, and grouper is one of the high-value species being cultured. Bacterial diseases are one of the problems encountered in grouper culture, resulting in the use of antibiotics for prophylactic and therapeutic treatments. However, information about the retention of metabolites of antibacterial drugs (e.g. FZ) in marine fishes is not available. In this study, the cyano-metabolite was biotransformed in the grouper

\footnotetext{
* To whom correspondence should be addressed. e-mail: unijohn @ ccms.ntu.edu.tw
} 


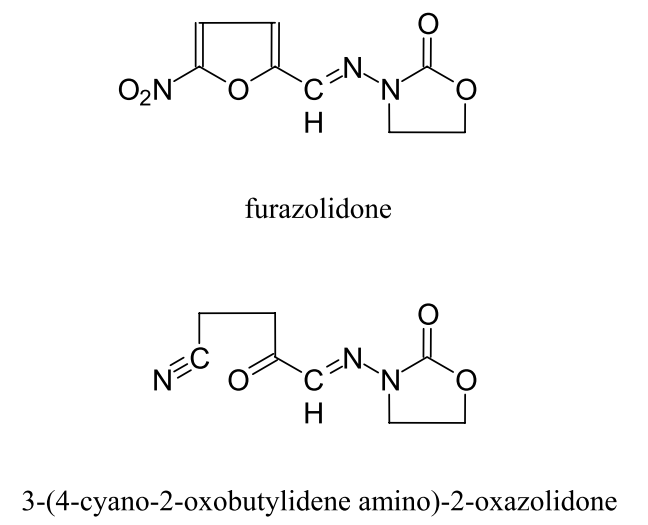

Figure 1.

hepatic supernatant incubated with FZ and its structure confirmed by nuclear magnetic spectroscopy and mass spectrometry. Thereafter, disposition of the cyano-metabolite in the orange-spotted grouper (Epinephelus coioides) treated with FZ by oral and bath administration was studied. Antibacterial activities of cyano-metabolite and its parent FZ were also compared using a susceptibility test.

\section{Materials and methods}

\section{Chemicals}

FZ, nicotinamide adenine dinucleotide phosphate (NADP), the reduced form of NADP (NADPH), glucose 6-phosphate (monopotassium salt) and tricaine methanesulphonate (MS-222) were purchased from Sigma Chemical Co. (St. Louis, MO, USA). Mueller-Hinton broth was purchased from Difco Laboratories (Sparks, MD, USA). All chemicals used were analytical or HPLC grade.

\section{Biosynthesis of cyano-metabolite using grouper liver}

Grouper livers were rapidly excised, rinsed and homogenized in 2 vols (v/w) of phosphate-buffered saline, $\mathrm{pH} 7.4$, containing $1.15 \% \mathrm{KCl}(\mathrm{PBS}-\mathrm{KCl})$ with a Biomixer (Nihonseiki Kaisha, Tokyo, Japan) in an icecold water bath. The homogenate was centrifuged at $9000 \mathrm{~g}$ for $20 \mathrm{~min}$ and the hepatic supernatant was inoculated in a reaction medium containing $10 \mathrm{mM}$
Table 1. Formation of 3-(4-cyano-2-oxobutylidene amino)-2-oxazolidone (cyano-metabolite) from furazolidone (FZ) using grouper hepatic supernatant under various independent factors at $37^{\circ} \mathrm{C}$ after a $1 \mathrm{~h}$ incubation.

\begin{tabular}{lcccc}
\hline \multicolumn{2}{l}{ Independent Factors } & & & \\
\hline $\begin{array}{l}\text { FZ } \\
\left(\mu \mathrm{g} \mathrm{ml}^{-1}\right)\end{array}$ & $\begin{array}{c}\text { Incubation } \\
\text { condition }\end{array}$ & $\begin{array}{c}\text { Liver } \\
\left(\mathrm{g} \mathrm{ml}^{-1}\right)\end{array}$ & $\begin{array}{c}\text { Formation of } \\
\text { Cyano-metabolite } \\
\left(\mathrm{nmol} \mathrm{g}^{-1} \text { liver }\right)\end{array}$ \\
\hline 25 & aerobic & 0.8 & NADP & 30.3 \\
50 & aerobic & 0.8 & NADP & 59.2 \\
100 & aerobic & 0.4 & NADP & 85.6 \\
100 & anaerobic & 0.4 & NADP & 326.7 \\
100 & anaerobic & 0.4 & NADPH & 404.5 \\
100 & anaerobic & 0.5 & NADPH & 278.9 \\
75 & anaerobic & 0.1 & NADPH & 415.7 \\
75 & anaerobic & 0.2 & NADPH & 574.3 \\
75 & anaerobic & 0.3 & NADPH & 632.0 \\
75 & anaerobic & 0.4 & NADPH & 150.8 \\
75 & anaerobic & 0.5 & NADPH & 51.5 \\
\hline
\end{tabular}

glucose 6-phosphate, $5 \mathrm{mM} \mathrm{MgCl}_{2}$, and $0.4 \mathrm{mM}$ cofactor (NADP or NADPH) in PBS-KCl. The ratios of hepatic supernatant to the incubation medium were different depending on the final liver concentrations listed in table 1. Metabolic incubations were initiated by the addition of various amount of FZ in dimethyl formamide. Incubations were performed at $37^{\circ} \mathrm{C}$ under anaerobic $\left(\mathrm{N}_{2}\right)$ or aerobic (air) conditions. After different incubation times, aliquots were taken for analysis and purification of the metabolite.

Isolation and identification of the cyano-metabolite

Aliquots of the incubated mixture were extracted three times with 2 vols (v/v) of ice-cold ethyl acetate. The combined ethyl acetate extract was filtered through filter paper topped with an anhydrous sodium sulfate layer. The filtrate was then evaporated to dryness at $37^{\circ} \mathrm{C}$ under vacuum. The residue was then redissolved in $30 \mathrm{ml}$ acetonitrile and extracted with $40 \mathrm{ml} n$-hexane to remove fat. The acetonitrile layer was separated from $n$-hexane and then evaporated to dryness at $37^{\circ} \mathrm{C}$ under vacuum. The defatted residues were again redissolved in $0.5-1 \mathrm{ml}$ acetonitrile-water mixture (20:80) and then filtered through a $0.2-\mu \mathrm{m}$ membrane filter before HPLC separation.

The HPLC system consists of a Waters 600 controller, a Waters 717 Plus autosampler and a Waters 996 
photodiode array (PDA) detector with the Millennium software (Waters Corp., Milford, USA) for data processing and output. A semipreparative reversed-phase, 6- $\mu \mathrm{m}$ Prep. Nova-Pak HR $\mathrm{C}_{18}$ column, $7.8 \mathrm{~mm} \times 30 \mathrm{~cm}$, was used for sample purification with a Nova-Pak $\mathrm{C}_{18}$ guard column (Waters Corp.) attached ahead. The mobile phase was an acetonitrile-water solution $(20: 80)$ at flow rate of $2 \mathrm{ml} \mathrm{min}-1$. The wavelength of PDA detector was set in the range $200-500 \mathrm{~nm}$. The injection volume for preparative separation was $200 \mu 1$.

The fractions with cyano-metabolite were monitored and collected by their chromatographic behaviour and ultraviolet spectra and were freeze-dried under vacuum. The residue of the cyano-metabolite was redissolved in mobile phase solution and chromatographed again isocratically to determine its purity and then subjected for further spectroscopic and mass spectrometric analyses.

Infrared (IR) spectra of the cyano-metabolite in $\mathrm{KBr}$ were recorded with a Nicolet (Madison, WI, USA) 510P FT-IR. Proton nuclear magnetic resonance $\left({ }^{1} \mathrm{H}-\right.$ NMR) spectra of cyano-metabolite were obtained with a Bruker (Karlsruhe, Germany) DMX$500 \mathrm{MHz}$ FT-NMR in $\mathrm{CDCl}_{3}$ using $\mathrm{Si}\left(\mathrm{CH}_{3}\right)_{4}$ as internal standard. Electron-impact mass (MS) spectra were obtained with a Finnigan (San Jose, CA, USA) MAT 95s mass spectrometer.

\section{Oral and bath administration of $F Z$}

The studies were conducted at the Tungkang Marine Laboratory of the Taiwan Fisheries Research Institute. Orange-spotted grouper, mean body weight $678 \pm 76 \mathrm{~g}$, were acclimatized for 2 weeks in cages in a $40 \times 15 \times 1.5 \mathrm{~m}$ pond with flow-through seawater of $30 \mathrm{ppt}$ salinity, $\mathrm{pH}$ 7.9. The experiments were performed at a water temperature of $30 \pm 2{ }^{\circ} \mathrm{C}$. The fish were fed with sand borer (Sillago sihama) twice a day. They were starved 1 day before FZ treatments.

The oral dose of FZ was administered in feed mixture at $50 \mathrm{mg} \mathrm{kg}^{-1}$ body weight. Before drug administration the fish were anaesthetized in well-aerated water containing $200 \mathrm{mgl}^{-1} \mathrm{MS}-222$ for 2-3 min and then weighed. FZ was mixed with the eel formulate feed, which was force-fed orally to the fish. Four fish were sampled for analysis before drug administration and at different intervals $(1,3,6,24,48$ and $72 \mathrm{~h})$ after administration.

For bath treatment, fish were exposed in FZ solution at a dose of $10 \mathrm{ppm}$ in a 500-litre FRP tank. After $24 \mathrm{~h}$ of bath treatment, the fish were transferred to fresh seawater. Four fish were sampled at different intervals during the bath $(0,0.25,1,3,6$ and $24 \mathrm{~h})$ and post-bath periods $(0.25,0.5,1,24,48$ and $72 \mathrm{~h})$. Both bathing and post-bathing treatments were performed at the same room temperature.

The blood of each fish sample was drawn from the caudal vein. The liver, kidney and muscle tissues were also collected separately. The blood was allowed to clot, and was centrifuged at $3000 \mathrm{rpm}$ under $4^{\circ} \mathrm{C}$ for $20 \mathrm{~min}$. The serum, liver, kidney and muscle were stored at $-80^{\circ} \mathrm{C}$ until analysed.

\section{Analysis of cyano-metabolite in fish}

Cyano-metabolite concentrations in fish tissues were determined by a reversed-phase HPLC with PDA detector. Serum samples, $2 \mathrm{ml}$ each, were agitated three times with $30 \mathrm{ml}$ ice-cold ethyl acetate and extracts were collected. Muscle (5g), liver $(5 \mathrm{~g})$ and kidney $(2 \mathrm{~g})$ samples were homogenized for $2 \mathrm{~min}$ in $30 \mathrm{ml}$ ice-cold ethyl acetate using Bio-mixer, and after centrifugation at $3000 \mathrm{rpm}$ for $5 \mathrm{~min}$ the supernatant was collected. This procedure was repeated three times and the collected supernatants from each tissue samples were combined into one sample. The ethyl acetate extracts were then filtered, defatted and analysed according to the method for cyano-metabolite isolation described above, except for tissue samples wherein residues were redissolved in $0.5 \mathrm{ml}$ mobile phase solution after drying and $100 \mu \mathrm{l}$ sample was injected to HPLC for analysis.

\section{Antibacterial activity}

A susceptibility test was used to evaluate the antibacterial activities of the cyano-metabolite and its parent FZ. Standard strain of Escherichia coli (CCRC 51731) and Vibrio anguillarum (CCRC 12908) were obtained from the Food Industry Research and Development Institute (Hsinchu, Taiwan). In the dilution susceptibility test, $100 \mu \mathrm{l}$ 


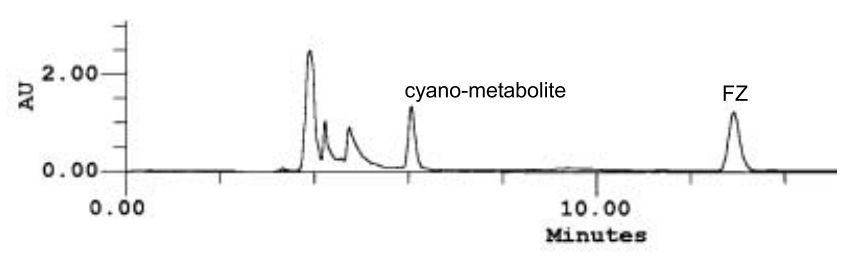

Figure 2.

Mueller-Hinton broth was dispensed in a 96-microwell plate containing a series of drug concentration in the range $0.01-10 \mu \mathrm{g} \mathrm{m}^{-1}$, and inoculated with $5 \times 10^{6} \mathrm{CFU} \mathrm{m}{ }^{-1}$ of bacteria. Each concentration had three replicates. The lowest concentration of test compound resulting in no growth after $24 \mathrm{~h}$ of incubation at $28^{\circ} \mathrm{C}$ was recorded as the minimum inhibitory concentration.

\section{Results}

Isolation and identification of cyano-metabolite

The cyano-metabolite of FZ was biotransformed in vitro from FZ using grouper hepatic supernatant. Fractions of cyano-metabolite were identified by its chromatographic behaviour, a retention time about 6 min (figure 2) in the HPLC system, and its ultraviolet spectrum with a $\lambda_{\max }$ at $271 \mathrm{~nm}$ using a PDA detector (figure 3a). The yield (table 1) of cyanometabolite varied under various biotransformation conditions, i.e. aerobic or anaerobic incubation, the concentration of FZ and hepatic supernatant, and the existence of NADP or NADPH cofactors. The optimum condition for cyano-metabolite formation was found when incubating $75 \mu \mathrm{g} \mathrm{ml}^{-1} \mathrm{FZ}$ and $0.3 \mathrm{~g} \mathrm{ml}^{-1}$ of hepatic supernatant in the reaction medium with NADPH as cofactor under an anaerobic condition at $37^{\circ} \mathrm{C}$ for $1 \mathrm{~h}$. The cyano-metabolite was found to be a major metabolite in this model system.

Pure cyano-metabolite was collected from the fractions of HPLC of similar spectral properties and identified by its nuclear magnetic resonance (NMR) and mass spectra. Electron-impact mass spectrum (EIMS) of cyano-metabolite revealed a low intensity $(\mathrm{M}+\mathrm{H})^{+}$molecular ion peak at $m / z 196$, with a base peak at $m / z$ 113. Two major fragments, the oxazolidone and aliphatic nitrile, were detected at $\mathrm{m} / z 87$ and 82 , respectively (figure $3 \mathrm{~b}$ ). ${ }^{1} \mathrm{H}-\mathrm{NMR}$ spectrum of
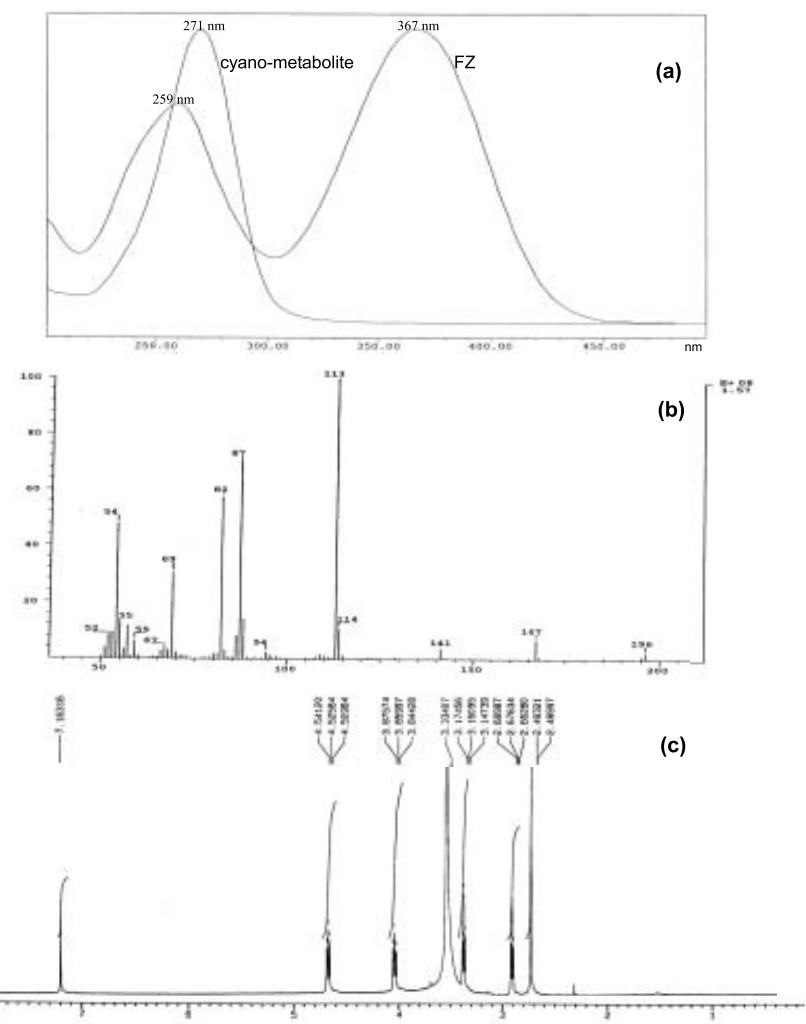

Figure 3.

cyano-metabolite in (dimethyl sulfoxide)- $d_{6}$ (figure $3 \mathrm{c})$ showed a singlet at $\delta 7.16(1 \mathrm{H}$, azomethine proton), two coupled triplets at $\delta 4.53(2 \mathrm{H})$ and $\delta 3.86$ $(2 \mathrm{H})$ of methylene protons in the oxazolidone ring, as well as another two coupled triplets at $\delta 3.16(2 \mathrm{H})$ and $\delta 2.68(2 \mathrm{H})$ of the vicinal methylene protons in the 4cyano-2-oxobutylidene moiety which was transformed from the nitro-furan of FZ. Infrared spectrum of cyano-metabolite revealed distinctive absorption bands at $2247 \mathrm{~cm}^{-1}$ (C三N stretching), $1775 \mathrm{~cm}^{-1}$ (carbonyl stretching in the oxazolidone ring) and $1703 \mathrm{~cm}^{-1}(\alpha, \beta$-unsaturated $\mathrm{C}=\mathrm{O}$ stretching). The white amorphous sample isolated was confirmed as 3-(4-cyano-2-oxobutylidene amino)-2-oxazolidone, a cyano-metabolite of FZ.

\section{Dispositions of cyano-metabolite in vivo}

In order to observe the disposition of the cyanometabolite of FZ in vivo, various amounts of 3-(4cyano-2-oxobutylidene amino)-2-oxazolidone were injected into the established HPLC for the calibration 

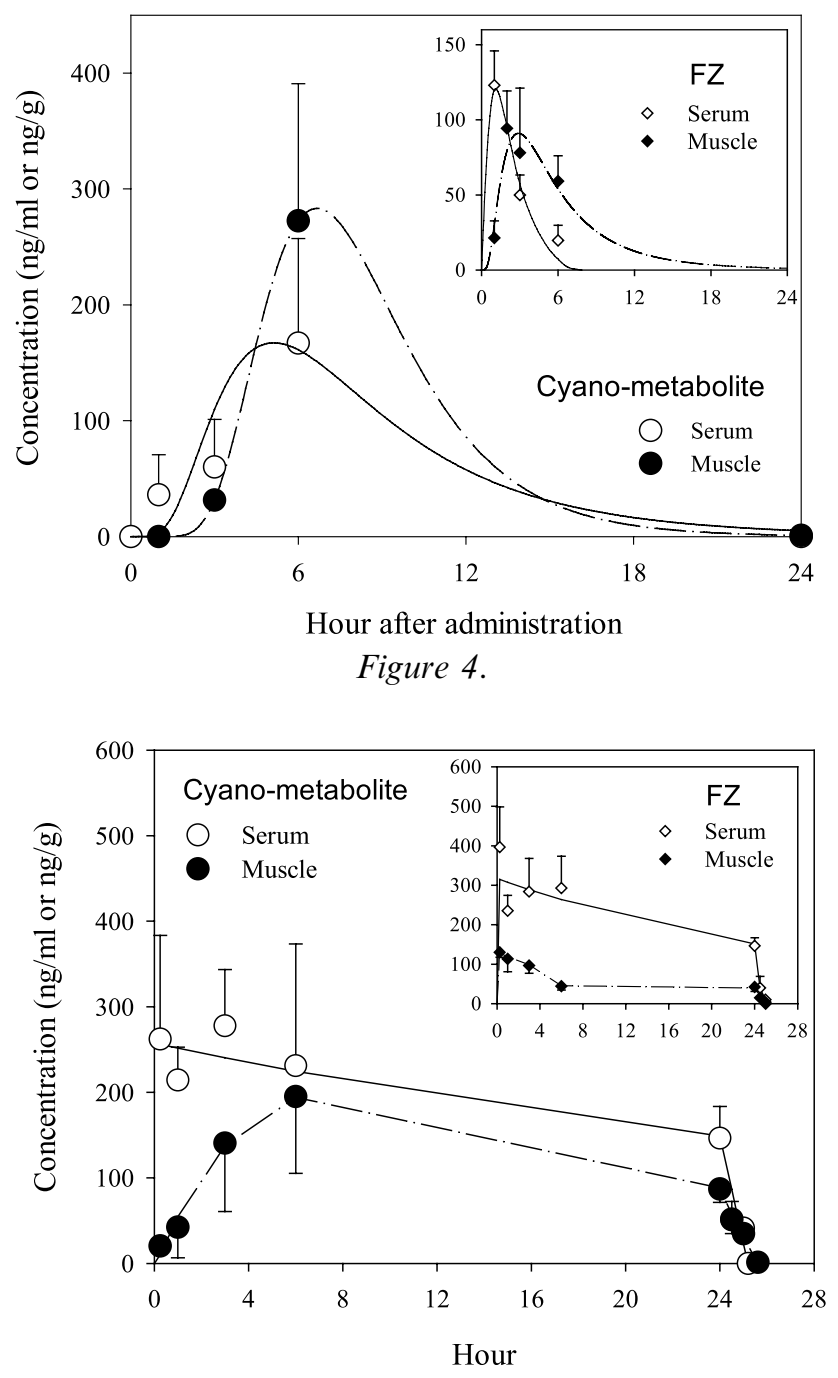

Figure 5.

curve. It was found that the HPLC response of cyanometabolite was linear over the range $0.1-10 \mu \mathrm{g} \mathrm{ml}^{-1}$ $(r=0.9999)$. A sample preparation procedure was also tested. The mean recoveries of the cyano-metabolite through this sample preparation determined by spiking control tissues with cyano-metabolite were $99.8 \pm 4.1 \%$ for serum, $98.6 \pm 3.5 \%$ for muscle, $53.1 \pm 7.4 \%$ for liver and $64.0 \pm 11.4 \%$ for kidney. Hence, in this experiment the detection limits of cyano-metabolite in serum, muscle, liver and kidney were $25 \mathrm{ng} \mathrm{ml}^{-1}$ and 10,10 and $25 \mathrm{ng} \mathrm{g}^{-1}$, respectively.

The dispositions of the cyano-metabolite in the orange-spotted grouper treated orally and in bath with FZ are shown in figures 4 and 5 and in table 2. The cyano-metabolite of FZ was found mainly distributed
Table 2. Disposition of 3-(4-cyano-2-oxobutylidene amino)-2-oxazolidone, a cyano-metabolite of furazolidone (FZ), in the orange-spotted grouper after oral and bath administration of $F Z$.

\begin{tabular}{|c|c|c|c|c|}
\hline \multirow[b]{2}{*}{ Parameters* } & \multicolumn{2}{|c|}{ Oral } & \multicolumn{2}{|c|}{ Bath } \\
\hline & Serum & Muscle & Serum & Muscle \\
\hline$T_{\max }(\mathrm{h})$ & 5.1 & 6.7 & 0.25 & 6 \\
\hline$C_{\max }\left(\mathrm{ng} \mathrm{ml}^{-1}\right.$ or $\left.\mathrm{ng} \mathrm{g}^{-1}\right)$ & 167.2 & 283.2 & 258 & 204 \\
\hline$t_{1 / 2 e}(\mathrm{~h})$ & 4.0 & & 0.5 & \\
\hline$T_{\text {withdraw }}(\mathrm{h})$ & 13.7 & 16.5 & 0.9 & 2.2 \\
\hline
\end{tabular}

in serum and muscle rather than in liver and kidney. After oral treatment of FZ, the peak cyano-metabolite concentration, $167.2 \mathrm{ng} \mathrm{ml}^{-1}$ in serum and $283.2 \mathrm{ng} \mathrm{g}^{-1}$ in muscle, was reached at 5.1 and $6.7 \mathrm{~h}$, respectively. The elimination half-life of cyano-metabolite measured from the terminal phase of the serum curve was $4 \mathrm{~h}$. Withdrawal periods of cyano-metabolite in serum and muscle were 13.7 and $16.5 \mathrm{~h}$ after administration, respectively. The appearance of cyano-metabolite significantly followed the parent FZ and both peak concentrations of cyano-metabolite in serum and muscle were higher than FZ (figure 4 and table 2).

During 24-h bath period of FZ, the peak concentrations of cyano-metabolite, $258 \mathrm{ng} \mathrm{ml}^{-1}$ in serum and $204 \mathrm{ng} \mathrm{g}^{-1}$ in muscle, were obtained at 0.25 and $6 \mathrm{~h}$, respectively. The half-life of cyano-metabolite was $0.5 \mathrm{~h}$ and was not detectable at 0.9 and $2.2 \mathrm{~h}$ in serum and muscle, respectively, after transferring the fish to fresh seawater. The distribution of cyano-metabolite in serum was as fast as its parent FZ, but its maximum concentrations in fish tissues were less than FZ (figure 5 and table 2).

\section{Antibacterial activity}

The minimum inhibitory concentrations of FZ against $E$. coli and $V$. anguillarum were 0.025 and $0.4 \mu \mathrm{g} \mathrm{ml}^{-1}$, respectively, but cyano-metabolite showed no antibacterial activity against both bacteria. The results of susceptibility test on E. coli and $V$. anguillarum revealed that the cyano-metabolite has no contribution to the antibacterial activity of FZ. 


\section{Discussion}

Although a variety of pathways have been described for nitrofuran metabolism, nitroreduction appears to be the most biologically significant of these biotransformations. In the present study, the furan ringopened metabolite 3-(4-cyano-2-oxobutylidene amino)-2-oxazolidone was biosynthesized from the incubation of FZ in grouper hepatic supernatant. Formation of this cyano-metabolite was affected by several factors during in vitro enzyme reaction. Our studies revealed that the formation of the cyanometabolite was higher in the presence of NADPH and under anaerobic conditions, and was obviously affected by the concentration of grouper liver. The enzymatic reduction of FZ to cyano-metabolite has been known occur either under aerobic or anaerobic conditions with either NADP or NADPH as cofactor. Abraham et al. (1984) reported that E. coli and rat liver enzymes catalysed reductive metabolism of FZ to cyano-metabolite under either aerobic or anaerobic conditions in vitro. They also demonstrated that this NADPH-dependent, oxygen-insensitive nitroreductase activity was localized to the microsomal fraction of rat liver and bacterial cell lysates. Tatsumi et al. (1981), on the other hand, reported that the milk xanthine oxidase and rat liver $9000 \mathrm{~g}$ supernatant were capable of reducing FZ to cyano-metabolite under strictly anaerobic conditions. Other metabolites were also reported to include a major one, 2,3-dihydro3-cyanomethyl - 2 - hydroxyl - 5 - nitro - 1a,2 - di(2-oxazolidin-3-yl)iminomethyl-furo[2,3-b]furan, and a minor metabolite, $\mathrm{N}$-(5-amino-2-furfurylidene)-3-amino2-oxazolidone by the same group. These two metabolites were not found in the grouper hepatic supernatant incubation system in this study.

The distribution and elimination of cyano-metabolite in grouper muscle and serum were as fast as its parent FZ after oral or bath treatments of FZ (Guo et al. 2002). The time required to reach the peak concentration of cyano-metabolite was about $4 \mathrm{~h}$ longer than FZ (figures 4 and 5 and table 2). Another study found that the peak concentrations of $\mathrm{FZ}, 120.9 \mathrm{ng} \mathrm{ml}^{-1}$ in serum and $93.3 \mathrm{ng} \mathrm{g}^{-1}$ in muscle, were reached at 1.1 and $2.0 \mathrm{~h}$, respectively, after oral administration of $\mathrm{FZ}$ and with an elimination half-life of $0.8 \mathrm{~h}$ (Guo et al. 2002). In the present study, peak concentrations of cyano-metabolite in serum and muscle after oral treatment of FZ were significantly higher than its parent FZ, especially in muscle with about a threefold difference. Meanwhile, the cyano-metabolite concentration in muscle was also twofold higher than FZ during a 24-h bath treatment with FZ. The withdrawal time of cyano-metabolite in grouper tissues was less than $17 \mathrm{~h}$ but longer than FZ (9h), especially in muscle. The cyano-metabolite was an important and major metabolite in this in vivo experiment, a fact also true in the in vitro biotransformation of $\mathrm{FZ}$ in grouper hepatic supernatant. Similar results were also reported in eel after bath treatment with FZ (Nakabeppu and Tatsumi 1984) and in rat after oral dose of FZ (Tatsumi et al. 1984). In swine, cyanometabolite was reported as a minor metabolite of FZ (Vroomen et al. 1987a). Results from this study show that cyano-metabolite in orange-spotted grouper was mainly distributed in serum and muscle rather than in liver and kidney. The same distribution characteristics were also observed in FZ after oral and bath treatments (Guo et al., 2002).

The cyano-metabolite of FZ was initially determined from the urine of rabbits receiving FZ orally (Tatsumi et al. 1978). It was demonstrated that this cyanometabolite of FZ is easily formed and discharged in the animals. Fast elimination of cyano-metabolite was also observed in adult swine, wherein no cyanometabolite in serum, muscle, liver and kidney were detectable at 24, 24, 2 and $2 \mathrm{~h}$, respectively, after oral treatment of FZ (Vroomen et al. 1987a).

Low levels of FZ and cyano-metabolite in kidney and liver were detected especially in the orally administered fish. It was inferred that FZ and cyano-metabolite were extremely reactive and metabolized to a more polar metabolites by enzymes or conjugated with macromolecules. Covalent binding of FZ with protein and DNA in vivo has been reported in piglets (Vroomen et al. 1986), while glutathione-dependent covalent binding of FZ to liver microsomal protein in vitro has been reported in rat (Vroomen et al. 1987c). A mercaptoethanol conjugate of FZ, 3-(4-cyano-3- $\beta$ hydroxyethylmercapto-2-oxobutylidene amino)-2-oxazolidone, which was an adduct of the open-chain acrylonitrile derivative of FZ, was formed by liver microsomes of swine via a reductive process of $\mathrm{FZ}$ (Vroomen et al. 1987b). It was speculated that cyanometabolite was the reactive intermediate of FZ to the mecaptoethanol derivative and have a short halflife.

Another important fact observed in this study is that the concentration of FZ was not maintained at the same level during the 24-h bath period and the concentration in muscle was lower than that in serum. 
Both FZ and cyano-metabolite in serum showed a gradual decline in concentration since the very beginning of $0.25 \mathrm{~h}$ after the immersion of fish in $10 \mathrm{ppm}$ drug solution. Cyano-metabolite in serum seemed to maintain the same decay rate as FZ but at a slightly lower concentration than FZ. This phenomena may be explained by the degradation of FZ in the bath solution that caused the gradual loss of serum concentration, or a self-regulating mechanism that prevented the fish from accumulating the free form of the drug by protein binding or enzyme metabolism. A peak concentration of the cyano-metabolite in muscle obtained $6 \mathrm{~h}$ after the bath treatment and a higher concentration of the cyano-metabolite than FZ in muscle, representing a result of a translocation of cyano-metabolite from serum and a transformation from muscle FZ. A fast loss of both FZ and cyanometabolite in either serum or muscle was also observed after transferring the fish from the bath solution to fresh seawater. Compared with the slow loss of tissue FZ in the orally administer fish, the bath treatment seems an easier way of removing the drug residues in the animal body. This result showed different routes of FZ metabolism while the drug was applied orally or by bathing. The mechanism causing the fast loss of drug needs further investigation, however.

In this study, the results of a susceptibility test on $E$. coli and $V$. anguillarum revealed that the cyanometabolite has no antibacterial activity in contrast to FZ. Vroomen et al. (1987a) also demonstrated that the cyano-metabolite was not mutagenic in the Salmonella/microsome test with and without metabolic activation. From the above results, it could be concluded that the cyano-metabolite has no contribution to the mutagenic and antibacterial activity of its parent FZ, but is absolutely related to covalent binding of FZ with macromolecules.

\section{Acknowledgements}

This study was one of the components of the research project [89-AST-1.2-FID-64(9)] financially supported by Council of Agriculture, Taiwan. The authors are grateful to Dr Mao-Sen Su, Deputy Director General, Taiwan Fisheries Research Institute (TFRI), and Dr Tzyy-Ing Chen, Director, Tungkang Marine Laboratory of TFRI, for kind support. Thanks are also due to Ms Yueh-O Hsu, Ms Chia-Yen Yang and $\mathrm{Mr}$ Chia-Hung Yang for assistance in laboratory work, and to Dr Eduardo Leaño for his contribution in the preparation of this manuscript.

\section{References}

Abraham, R. T., Knapp, J. E., Minnigh, M. M., Wong, L. K., Zemotis, M. A., and Alvin, J. D., 1984, Reductive metabolism of furazolidone by Escherichia coli and rat liver in vitro. Drug Metabolism and Disposition, 12, 732-741.

Guo, J. J., Chou, H. N., and Liao, I C., 2002, Pharmacokinetics of furazolidone in the orange-spotted grouper, Epinephelus coioides. Food Additives and Contaminants. (submitted).

Hoogenboom, L. A. P., Pastoor, F. J. H., Clous, W. E., Hesse, S. E., and KuIPER, H. A., 1989, The use of porcine hepatocytes for biotransformation studies of veterinary drugs. Xenobiotica, 19, 1207-1219.

Law, F. C. P., Abedini, S., He, Y. T., and Greenlees, K. J., 1992, Metabolic disposition of ${ }^{14} \mathrm{C}$-furazolidone $\left({ }^{14} \mathrm{C}-\mathrm{FZ}\right)$ in trout following oral administration of medicated feed. Pharmacologist, 34, 181.

Law, F. C. P., and Meng, J., 1996, Binding of ${ }^{14}$ C-furazolidone metabolites to the muscular and hepatic protein of trout. Food Additives and Contaminants, 13, 199-209.

Nakabeppu, H., and Tatsumi, K., 1984, Metabolism of furazolidone in eels. Chemical and Pharmaceutical Bulletin, 32, 4193-4195.

Plakas, S. M., El Said, K. R. and Stehly, G. R., 1994, Furazolidone disposition after intravascular and oral dosing in the channel catfish. Xenobiotica, 24, 1095-1105.

Sugimoto, N., Kashiwagi, S., and Matsuda, T., 1979, Research on the change in concentration of furazolidone $(N$-(5-nitro-2-furyliden)-3-amino-2-oxazolidone) in fish muscle using a fluorescent spectrophotometric determination. Bulletin of the Japanese Society of Scientific Fisheries, 45, 353-362.

Swaminathan, S., and Lower, G., 1978, Biotransformations and excretion of nitrofurans. Carcinogenesis: Nitrofurans, vol. 4, edited by G. T. Bryan (New York: Raven), pp. 59-79.

Tatsumi, K., Nakabeppu, H., Takahashi, Y., and Kitamura, S, 1984, Metabolism in vivo of furazolidone: evidence for the formation of a open-chain carboxylic acid and $\alpha$-ketoglutaric acid from the nitrofuran in rats. Archives of Biochemistry and Biophysics, 234, 112-116.

Tatsumi, K., OU, T., Yamada, H., Yoshimura, H., Koga, H., and HorIUCHI, T., 1978, Isolation and identification of the metabolite of $N$-(5-nitro-2-furfurylidene)-3-amino-2-oxazolidone (furazolidone). Journal of Pharmacobio-Dynamics, 1, 256-261.

Tatsumi, K., Yamada, H., Yoshimura, H., and Kawazoe, Y., 1981, Metabolism of furazolidone by milk xanthine oxidase and rat liver $9000 \mathrm{~g}$ supernatant: formation of a unique nitrofuran metabolite and an aminofuran derivative. Archives of Biochemistry and Biophysics, 208, 167-174.

Vroomen, L. H. M., Berghmans, M. C. J., Hekman, P., Hoogenboom, L. A. P., and Kuiper, H. A., 1987a, The elimination of furazolidone and its open-chain cyano-derivative from adult swine. Xenobiotica, 17, 1427-1435.

Vroomen, L. H. M., Berghmans, M. C. J., Leeuwen, P. Van, Struija, T. D. B. Van, Vries, P. H. A. De, and Kuiper, H. A., 1986, Kinetics of ${ }^{14} \mathrm{C}$-furazolidone in piglets upon oral administration during 10 days and its interaction with tis- 
sue macro-molecules. Food Additives and Contaminants, 3, 331346.

Vroomen, L. H. M., Groten, J. P., Muiswinkel, K. V., Van VELduizen, A., and VAN Bladeren, P. J., 1987b, Identification of reactive intermediate of furazolidone formed by swine liver microsomes. Chemico-Biological Interactions, 64, 167-179.

Vroomen, L. H. M., van Ommen, B.,, and Berghmans, M. C. J., $1987 \mathrm{c}$, Quantitative studies of the metabolism of furazolidone by rat liver microsomes. Toxicology In-Vitro, 1, 97-104. 
Copyright $\odot 2003$ EBSCO Publishing 